\title{
PRODUÇÃO DE ELEMENTOS CONSTRUTIVOS PARA FORMA DE VIGAS REFORÇADO REFORÇACO COM FIBRAS VEGETAIS
}

\author{
Priscila Araujo ${ }^{1}$; Paulo Lima ${ }^{2}$ \\ 1. Priscila Araujo de Souza PROBIC/UEFS, Graduando em Engenharia Civil, Universidade Estadual de Feira de \\ Santana, e-mail: pri_aaraujo@hotmail.com \\ 2. Orientador: Paulo Roberto Lopes Lima, Departamento de Tecnologia, Universidade Estadual de Feira de Santana, \\ e-mail: lima.prl.uefs@gmail.com
}

PALAVRAS-CHAVE: Fibrocimento; Fibra vegetal; Avaliação experimental.

\section{INTRODUÇÃO}

A indústria da construção civil é um dos setores que mais consome recursos da natureza. Na tentativa de redução do impacto causado ao ambiente buscam-se cada vez mais formas de se utilizar materiais e sistemas construtivos mais apropriados, isto é, que sejam de fontes renováveis, com baixo custo energético e que tenham consumos mínimos.

Desde o início da década de 70 têm-se optado pelo uso sistemático de fibrocimento com fibras vegetais em elementos para cobertura para substituir o uso de telhados em palhas. Sua potencialidade como elemento semi-estrutural foi verificada na produção de telhas canaletas e na produção de formas perdidas para lajes (SCHAFER; BRUNSSEN,1990). Porém, devido a problemas de incompatibilidade química entre o cimento e a fibra vegetal, a produção de elementos construtivos foi interrompida e novas aplicações de fibras vegetais em elementos construtivos voltaram a ser avaliadas apenas a partir da década de 90 e confirmaram o seu potencial (SCHAFER; BRUNSSEN,1990; FARIAS FILHO et al,2000; SAVASTANO JR, 2000; TOLEDO FILHO et al,2003). Nesse contexto, esse trabalho tem como objetivo geral o desenvolvimento de uma forma permanente pré-fabricada de concreto com reforço de fibras curtas de sisal, com uso destinado à produção de vigas de concreto armado.

\section{MATERIAL E MÉTODOS OU METODOLOGIA}

Foram utilizadas fibras provenientes do município de Valente, Bahia. As fibras de sisal precisaram, inicialmente, serem lavadas por cerca de 15 minutos em água morna para a retirada de mucilagem e posteriormente ser hornificadas. Segundo Ferreira et al. (2012), o processo de hornificação tem como objetivo melhorar a aderência entre a fibra e a matriz e consiste em submeter as fibras a sucessivos ciclos de molhagem e secagem, fazendo com que o diâmetro das fibras diminua e consequentemente sua capacidade de absorção de água. No presente trabalho, as fibras ficaram em imersão em água à temperatura ambiente por 3 horas, depois passaram pelo processo de secagem em estufa. A temperatura inicial da estufa era de $45{ }^{\circ} \mathrm{C}$ e era aumentada em $1{ }^{\circ} \mathrm{C}$ a cada minuto até atingir $80^{\circ} \mathrm{C}$, temperatura na qual permanecia por 16 horas, e, por fim, era feito o resfriamento em $1{ }^{\circ} \mathrm{C}$ por minuto até atingir a temperatura ambiente. Para cada lote de fibras foram realizados 5 ciclos de hornificação. Terminados os ciclos de hornificação, as fibras precisaram ser penteadas e cortadas em tamanhos de $40 \mathrm{~mm}$. 
Para fins de caracterização inicial dos outros componentes do compósito foram realizados ensaios para determinação da massa específica destes. Para o cimento, o ensaio é estabelecido pela NBR NM 23 (ABNT, 2001) e para o agregado miúdo pela NBR NM 52 (ABNT, 2009). No caso da sílica ativa e da cinza volante, por ausência de normas próprias e tendo em vista suas granulometrias e funções próximas ao do cimento, foi utilizado o mesmo ensaio.

Essas adições minerais (sílica ativa e cinza volante) foram utilizadas com o intuito de reduzir a alcalinidade da matriz cimentícia. Foi utilizado um aditivo superplastificante à base de policarboxilato (MC-POWERFLOW 1108 - MC BAUCHEMIE) com massa específica de $1,09 \mathrm{~g} / \mathrm{cm}^{3}$ e relação de $30 \%$ de sólidos para o desenvolvimento de matriz autoadensável. Com o objetivo de evitar a exsudação e a segregação e manter a coesividade do compósito foi utilizado um agente modificador de viscosidade à base de polímero de alto peso molecular (Rheomac UW 410® - Basf®).

O compósito tomado como ponto de partida para os estudos foi o mesmo desenvolvido por Roque (2015), com traço em massa 0,5:0,1:0,4:1,0:0,35 (cimento: sílica ativa: cinza volante: areia: água). Posteriormente foi adotado o traço em massa de 0,45:0,15:0,4:1,0:0,35 (cimento: sílica ativa: cinza volante: areia: água). Os volumes de fibra utilizados foram de $1,5 \%, 2,2 \%$ e $3,2 \%$.

De acordo com Roque (2015), com o objetivo de manter a fluidez das misturas, a consistências da matriz cimentícia autoadensável foi fixada em $400 \pm 10 \mathrm{~mm}$ e dos compósitos com fibra de sisal foram $270 \pm 10 \mathrm{~mm}$, quando houve necessidade foram aplicados os golpes. A avaliação da consistência do compósito foi realizada conforme indica a NBR 13276/2005.

Por fim, para avaliar se as placas cimentícias reforçadas com fibras apresentavam o comportamento adequado de múltipla fissuração, aumento de tenacidade e ganho de resistência pós fissuração, foram realizados ensaios de flexão a 4 pontos com 14 dias de moldagem das placas.

\section{RESULTADOS E/OU DISCUSSÃO}

1- Os ensaios de massa específica dos materiais utilizados para a dosagem do compósito apresentaram os seguintes resultados mostrados na tabela abaixo:

Tabela 1. Dados dos ensaios de massa específica

\begin{tabular}{cc}
\hline Material & $\boldsymbol{\rho}\left(\mathbf{g} / \mathbf{c m}^{\mathbf{3}}\right)$ \\
\hline & \\
Cimento & 3,08 \\
Sílica ativa & 2,21 \\
Cinza volante & 1,93 \\
Areia & 2,61 \\
\hline
\end{tabular}

Legenda. Dados obtidos pela autora

2 - Moldagens

Para a realização da primeira moldagem utilizou-se como referência o traço 0,5:0,1:0,4:1,0:0,35 (cimento: sílica ativa: cinza volante: areia: água) de Roque (2015) 
com correção de água do superplastificante e 1,5\% de fibras secas. Como essa matriz cimentícia não obteve o espalhamento esperado de $400 \pm 10 \mathrm{~mm}$, optou-se por utilizar o traço de 0,45:0,15:0,4:1,0:0,35 nas duas dosagens seguintes que ocorrem com fibras úmidas contendo respectivamente $2,2 \%$ e $3,2 \%$ de fibras. A partir do ensaio de flexão em 4 pontos foram obtidas as curvas características de tensão versus deslocamento dos compósitos, conforme figuras 1,2 e 3 .

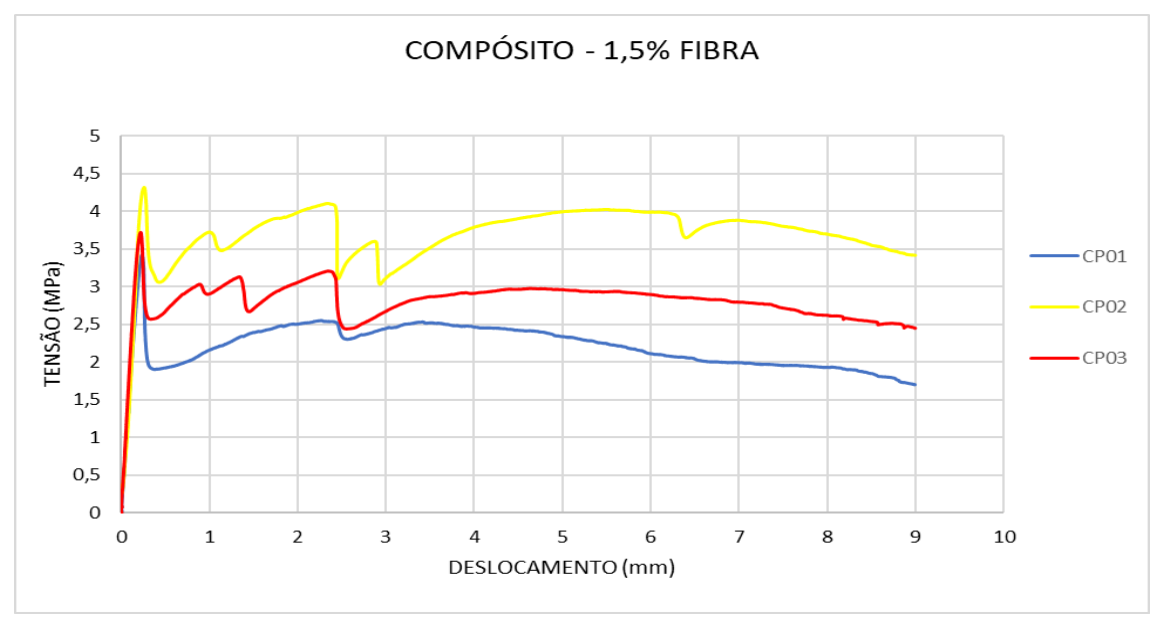

Figura 1: Ensaio de flexão em 4 pontos- Compósito 1. Fonte: Autora

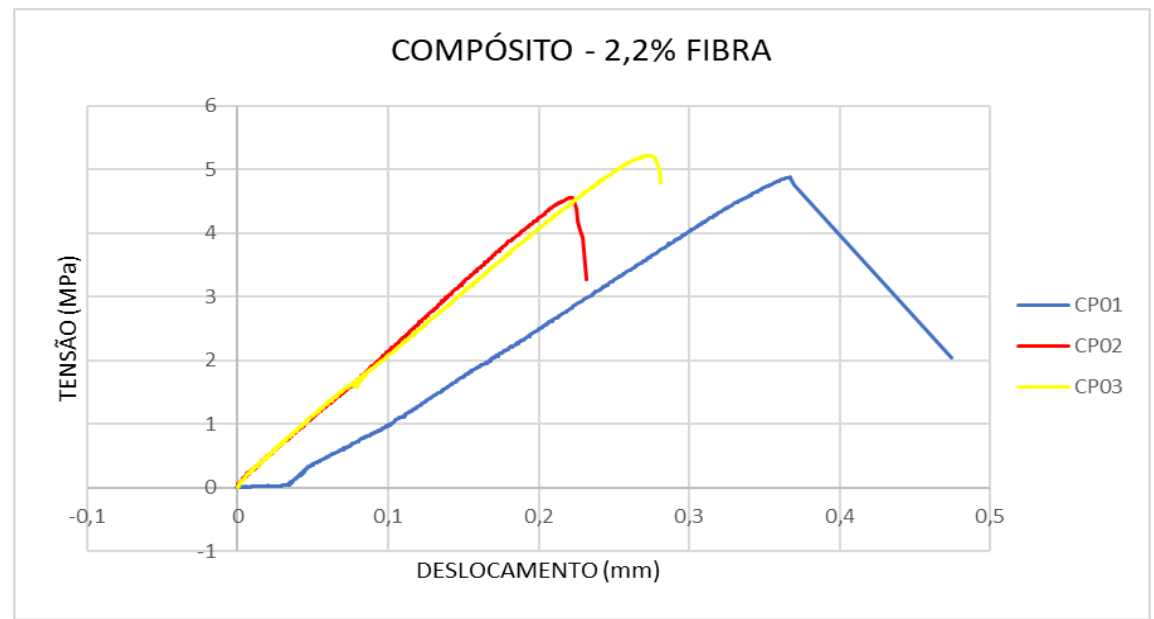

Figura 2: Ensaio de flexão em 4 pontos- Compósito 2. Fonte: Autora

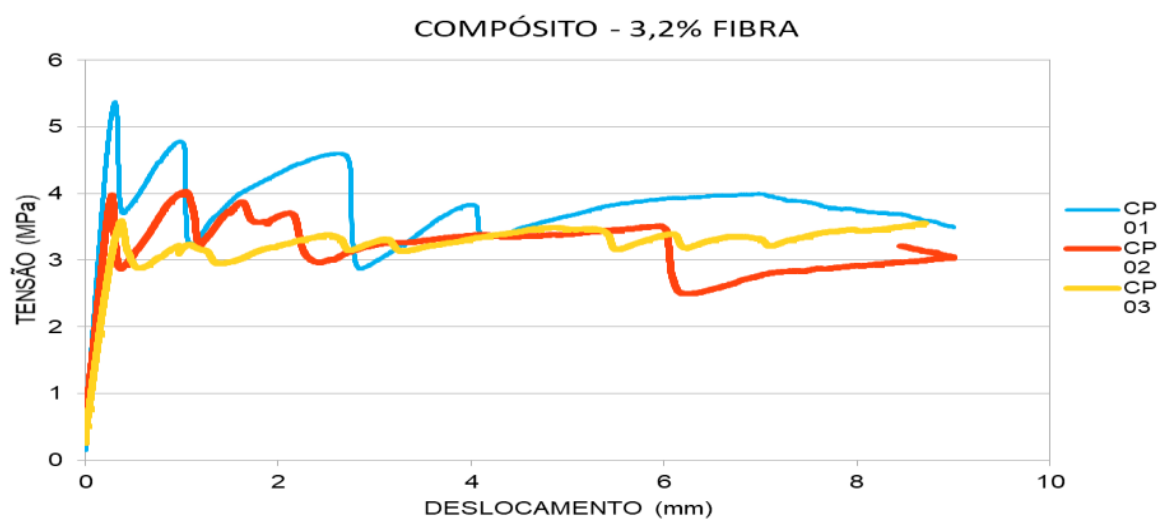

Figura 3: Ensaio de flexão em 4 pontos- Compósito 3. Fonte: Autora

Os resultados dos ensaios de flexão apontam que o compósito com maior percentual de fibras foi o que mais se aproximou do resultado esperado, ou seja, foi o que apresentou 
maiores ganhos de resistência após a primeira fissura. Como consequência, o compósito com 3,2\% de fibras foi o único que apresentou múltiplas fissurações. Através da análise dos gráficos é possível observar também que o percentual de fibras não é o único fator importante para se analisar a resistência dos compósitos, pois percebe-se que o compósito com 1,5\% de fibras e com correção da água do superplastificante apresentou um comportamento melhor no que se refere ao ganho de resistência após a primeira fissura quando comparado com o compósito com 2,2\% e sem correção, além disso os traços diferentes das matrizes cimentícias também exerceram influência nos resultados.

\section{CONCLUSÃO}

A partir da avaliação dos resultados dos ensaios realizados, verificou-se que o traço usado nas moldagens 2 e 3 apresenta o resultado esperado que é produzir uma matriz cimentícia auto adensável. No entanto, a placa com apenas $2,2 \%$ de fibras não se comportou na ruptura como desejado, visto que apresentou fissuração única. Ao se trabalhar com fibras espera-se que o material apresente melhor comportamento após a fissuração e apresente múltiplicas fissurações, com um menor espaçamento entre elas. A placa que chegou mais próxima do resultado esperado foi a com 3,2\% de fibras. Entretanto, é necessário que os estudos continuem para que se avalie o teor de fibras ideal para que se possa obter boa trabalhabilidade para moldagem das formas e boa resistência mecânica.

\section{REFERÊNCIAS}

FARIAS FILHO, J., JOSELMA, S. R e TOLEDO FILHO, R. D. "Potencialidades da metacaolinita e do tijolo queimado moído como substitutos parciais do cimento Portland". Revista Brasileira de Engenharia Agrícola e Ambiental, V. 4, no 3. p. 437444. 2000.

FERREIRA, S. L. et al. Influência de ciclos de molhagem-secagem em fibras de sisal sobre a aderência com matrizes de cimento Portland. Revista Matéria, v. 17, n. 2, 2012.

ROQUE, Alex Borges. Elemento construtivo de fibrocimento contendo resíduo de concreto e fibra de sisal para uso para uso como enchimento de lajes pré-moldadas. 2015. Dissertação (Mestrado em Engenharia Civil)-Universidade Estadual de Feira de Santana, Feira de Santana, 2015.

SAVASTANO JR, H. Materiais à base de cimento reforçados com fibra vegetal: Reciclagem de resíduos para a construção de baixo custo. 2000. Tese (Livre Docência) - Departamento de Engenharia de Construção Civil - Escola Politécnica da Universidade de São Paulo, São Paulo-SP.

SCHAFER, H. G.; BRUNSSEN, G. W. Sisal-fibre reinforced lost form work for floor slabs vegetable plants and their fibres as building material, In VEGETABLE PLANTS AND THEIR AS BUILDING MATERIAL RILEM N.7. Salvador, Proceedings, 1990.

TOLEDO FILHO, R.D.; GHAVAMI, K.; ENGLAND, G.L; SCRINEVER, K. Development of vegetable fibre-mortar composites of improved durability. Cement And Concrete Composites. V.25, N.2, p.185 - 196, 2003. 